\title{
Bacterial metabolism of side chain fluorinated aromatics: cometabolism of 3-trifluoromethyl(TFM)-benzoate by Pseudomonas putida (arvilla) mt-2 and Rhodococcus rubropertinctus N657
}

\author{
Karl H. Engesser ${ }^{1}$, Ronald B. Cain ${ }^{2}$, and Hans J. Knackmuss ${ }^{1}$ \\ 1 Institut für Mikrobiologie der Universität Stuttgart, D-7000 Stuttgart 1, Federal Republic of Germany \\ ${ }^{2}$ Department of Agricultural Biology, University of Newcastle Upon Tyne, Newcastle Upon Tyne, NE11 7RV, UK
}

\begin{abstract}
The TOL plasmid-encoded enzymes of the methylbenzoate pathway in Pseudomonas putida mt-2 cometabolized 3-trifluoromethyl (TFM)-benzoate. Two products, 3-TFM-1,2-dihydroxy-2-hydrobenzoate (3-TFM-DHB) and 2-hydroxy-6-oxo-7,7,7-trifluoro-hepta-2,4-dienoate (7TFHOD) were identified chemically and by spectroscopic properties. TFM-substituted analogues of the metabolites of the methylbenzoate pathway were generally converted at drastically reduced rates. The catechol-2,3-dioxygenase from Pseudomonas putida showed moderate turnover rates with 3-TFM-catechol. The catechol-1,2-dioxygenase of Rhodococcus rubropertinctus N657 was totally inhibited by 3-TFM-catechol and did not cleave this substrate. Hammetttype analysis showed the catechol-1,2-dioxygenase reaction to be strongly dependent on the electronic nature of the substituents. Electronegative substituents strongly inhibited catechol cleavage. The catechol-2,3-dioxygenase reaction, however, was only moderately sensitive to electronegative substituents.
\end{abstract}

Key words: TOL-plasmid - Side chain fluorinated aromatics - Hammett-plot - Catechol-dioxygenases Pseudomonas putida mt-2 - Rhodococcus rubropertinctus N657

Many man-made organic compounds containing structural elements like halogen atoms, nitro or sulfonic acid groups tend to persist in the environment (Grady 1985). The fact that the unsubstituted organic parent compounds or methylsubstituted structural analogues are readily biodegraded under appropriate conditions (Gibson 1971; Dagley 1984), indicates that these structural elements impede biological breakdown. The mechanism of the biological persistence of halogenated aromatic compounds in bacteria has been investigated with halobenzoates as model compounds (Dorn and Knackmuss 1978; Reineke and Knackmuss 1978a,b; Schmidt et al. 1980; Schmidt and Knackmuss 1980; Reineke et al. 1982). In addition to raising problems of permeability and inducer function of the substrates, substitution of hydrogen by halogen exertes a strong influence on binding of those substrates as well as on their turnover rates (Reineke

Offprint requests to: $\mathrm{K}$.H. Engesser
1984). In the present study the effect of substitution of side chain hydrogen by fluorine is investigated using trifluoromethyl-substituted benzoates as model compounds. Although trifluoromethyl-substituted aromatics are frequently encountered in river water (Maier et al. 1978) the influence of side-chain perfluoroalkyl substitution on bacterial degradation of aromatics has received scant attention. The use of model compounds should therefore reveal basic knowledge on the mechanism of persistence of this class of compounds.

Although hydrogen substitution by fluorine is accompanied by only a small increase in molecular size, strong effects on enzymic turnover rates (Schreiber et al. 1980; Engesser et al. 1980; Thakker et al. 1984; Teipel et al. 1968; Buist and Findlay 1984) have been observed. In Pseudomonas sp. B13 for example dioxygenation rates of fluorobenzoates are decreased to 15 to $50 \%$ of that found with the parent compound (Reineke and Knackmuss 1978a); the strong electronegative character of the fluorine atom reduces reaction rates of electrophilic aromatic substitution. The present investigation with trifluoromethylbenzoates describes a similar effect on the cooxidation rates of benzoate by Pseudomonas putida mt-2 (PaW) and by the Gram-positive organism Rhodococcus rubropertinctus N657 when the trifluoromethyl group occurs as a substituent. The organisms were grown on 3- or 4-methylbenzoate as structural analogues of the trifluoromethyl-benzoates. Both substrates were degraded via methylcatechols but whereas R. rubropertinctus $\mathrm{N} 657$ uses a modified ortho-pathway (Miller 1981), Pseudomonas putida $\mathrm{mt}-2$ dissimilates these substrates via the meta-cleavage pathway (Murray et al. 1972; Wong and Dunn 1974).

In an accompanying paper corresponding effects are analyzed by use of 4-isopropylbenzoate (cymene) degrading bacteria.

\section{Materials and methods}

Chemicals. The isomeric trifluoromethylbenzoates were obtained from Bayer AG, Leverkusen, FRG. All other benzoates were bought from Aldrich Chemical Company, Steinheim, FRG as were catechol, 3- and 4-methylcatechol, 3-methoxycatechol and 3-isopropylcatechol. 3-Ethylbenzoate was obtained from K\&K Laboratories Inc., New York. 3-Trifluoromethyl (TFM)-catechol was produced biologically using Rhodococcus rubropertinctus N657. It was characterized by comparison with a sample synthesized with 
highly purified 1,2-dihydroxy-2-hydro-benzoate (DHB)-dehydrogenase (a gift from W. Reineke) acting on 3-TFM1,2-dihydroxy-2-hydrobenzoate. $\mathrm{NAD}^{+}$was obtained from Sigma Chemical Company, St. Louis, MO, USA. 2Hydroxy-6-oxo-hepta-2,4-dienoate, 2-hydroxy-7-methyl-6oxo-octa-2,4-dienoate and 2-hydroxy-6-oxo-7,7,7-trifluorohepta-2,4-dienoate were biologically produced using heated crude extracts of Pseudomonas putida mt-2 (Murray et al. 1972; Wong and Dunn 1974). Chemicals for media were of the highest grade commercially available.

Organisms. Pseudomonas putida mt-2 (ATCC 33015) was a gift from P.A. Williams, Bangor, Wales. Alcaligenes eutrophus (ATCC 17697) and its derived mutant B9 were kindly provided by G.D. Hegeman, University of Indiana, Bloomington. Pseudomonas sp. B13 is deposited in the Deutsche Sammlung für Mikroorganismen (DSM 624). Rhodococcus rubropertinctus N657 originated from the collection assembled for an extensive numerical taxonomic survey of the nocardioform actinomycetes by M. Goodfellow (Tsukamura 1982; Goodfellow and Minnikin 1984).

Growth conditions. A mineral medium was used as described previously (Dorn et al. 1974). The organisms were grown in intended Erlenmeyer flasks ( 11 capacity), and incubated at $30^{\circ} \mathrm{C}$ on a rotary shaker $(150 \mathrm{rpm})$.

Alternatively a $10 \mathrm{l}$-Biostat-fermenter was used (Fa. Braun, Melsungen, FRG). Cells were harvested by centrifugation at $20,000 \times \mathrm{g}$ for $10 \mathrm{~min}$ and resuspended in $50 \mathrm{mM}$ phosphate buffer $\mathrm{pH} 7.4$ to an optical density $(\lambda=546 \mathrm{~nm})$ of about 10 for cometabolism experiments. To prepare crude extracts cells were disrupted in a French pressure cell at $128 \mathrm{MPa}$ (Aminco, Silver Springs, MD, USA). The supernatant was centrifuged at $100,000 \times g$ for $1 \mathrm{~h}$. Protein concentrations were determined as previously described (Schmidt and Knackmuss 1980).

Chromatographical methods. TLC-plates were prepared as described (Hartmann et al. 1979). Analysis was performed using solvent system I: diisopropylether/formate/water 200/ 7/3 (by vol.) and solvent system II: trichloromethane/ acetone $(80 / 20)$ (by vol.). Spots were detected with a UV lamp at $254 \mathrm{~nm}$ or $366 \mathrm{~nm}$. HPLC analysis was performed as described previously (Schmidt et al. 1980; Brilon et al. 1981) except that eluent $B$ contained $75 \%$ methanol only.

Spectroscopical methods. For ${ }^{1} \mathrm{H}-\mathrm{NMR}$ measurements a Varian spectrometer (model HA 100) (Varian Ltd, Bremen, FRG) was used. MS and GC-MS was performed with the model 21-492 from DuPont, Monrovia and a GC-MS combination from Varian Ltd., Bremen, FRG.

Isolation and derivatization of metabolites. Extraction procedures were described previously (Hartmann et al. 1979). Methylesters were prepared using $\mathrm{N}$-methyl-N-nitroso-ptoluenesulfonamide (Schmidt et al. 1980). Hydrolysis of 6TFM-2-picolinic acid was performed in $95 \%$ sulfuric acid at $280^{\circ} \mathrm{C}$ and monitored by HPLC. 2,6-Dipicolinic acid and the product of hydrolysis had retention volumina $(100 \% \mathrm{~A}$ eluent) of 7.7 and $7.6 \mathrm{ml} \mathrm{rsp}$. All other isomers showed retention volumina of $\leq 1.7 \mathrm{ml}$. $\mathrm{R}_{\mathrm{f}}$-values using TLC with methylated 2,6-dipicolinic acid and the product of hydrolysis also proved to be identical $\left(R_{f}=0,69\right.$ in solvent system II; $R_{f}=0.22$ with trichloromethane as mobile phase).
Enzyme assays. Benzoate dioxygenase and toluate dioxygenase were assayed using whole cells (Reineke and Knackmuss 1978a). 1,2-Dihydroxy-2-hydrobenzoate (DHB) dehydrogenases were assayed as described (Reineke and Knackmuss 1978b) except that phosphate buffer was used (50 $\mathrm{mM} \mathrm{pH} \mathrm{7.4).}$

Catechol-1,2-dioxygenases were assayed in Tris/HCl buffer $(33 \mathrm{mM} \mathrm{pH} 8)$ using molar absorption coefficients of muconic acids determined previously (Dorn and Knackmuss 1978). Tests were performed without EDTA as there was no measurable activity for the product-metabolising enzyme, muconate cycloisomerase. $K_{\mathrm{i}}$ and $K_{\mathrm{m}}$ values were determined in $50 \mathrm{mM}$ phosphate buffer, $\mathrm{pH}$ 7.4. Catechol2,3-dioxygenase and 2-hydroxy-6-oxo-hepta-2,4-dienoate hydrolase were assayed with catechols (Reineke et al. 1982) and their corresponding ring cleavage products respectively (Reineke et al. 1982) as substrates. Molar absorption coefficients were determined in $50 \mathrm{mM}$ phosphate buffer $\mathrm{pH}$ 7.4; the absorption maximum and molar extinction coefficients were found to be $\varepsilon=26,900(\lambda=385 \mathrm{~nm})$ for 2-hydroxy-6-oxo-7,7,7-trifluorohepta-2,4-dienoate; $\varepsilon=$ $12,000(\lambda=305 \mathrm{~nm})$ for the 6-methylester of 2-hydroxyhexa2,4-dien-1,6-dioicacidoate and $\varepsilon=13,000(\lambda=389 \mathrm{~nm})$ for 2-hydroxy-7-methyl-6-oxo-octa-2,4-dienoate.

\section{Results}

\section{Cometabolism of TEM-benzoates}

None of the three trifluoromethyl (TFM)-substituted benzoates served as a growth substrate for Pseudomonas putida $\mathrm{mt}-2$. Only very weak induction of the TOL-plasmid coded enzymes of methylbenzoate degradation (Wong and Dunn 1974) were observed within $28 \mathrm{~h}$ when succinategrown cells were incubated in the presence of 3-TFMbenzoate. The concentration of 3-TFM-benzoate $(2 \mathrm{mM})$ decreased by only about $5 \%$. Enzyme levels induced by 3 TFM-benzoate were about $2-5 \%$ of those induced with 3methylbenzoate (data not shown).

Relative oxidation rates of differently substituted benzoates by 3-methylbenzoate grown cells of Pseudomonas putida $\mathrm{mt}-2$ are shown in Table 1 . Turnover rates were estimated by HPLC analysis of the decreasing concentration of benzoates in the culture fluid. This method was usually more accurate than following polarographic analysis of $\mathrm{O}_{2}$ uptake rates which were often falsified by other $\mathrm{O}_{2}$ consuming reactions.

Of the three isomeric TFM-benzoates only the 3-isomer was substantially oxygenated; little or no activity could be detected for the 4- or 2-isomer. This reflected both the steric as well as the electronic influence of the TFM substituents, because even bulkier substituents (such as the ethyl group in 3-and 4-ethylbenzoate) did not reduce turnover rates to such an extent (Table 1).

Comparison with unsubstituted benzoate as substrate indicated that TFM-benzoates were poorly bound by the toluate dioxygenase, because dioxygenation of benzoate was largely unaffected by equimolar amounts of TFM-benzoates. Turnover of these substrates started only after the benzoate concentration was lowered substantially $(\leq 0.75 \mathrm{mM})$.

\section{Products of 3-TFM-benzoate cometabolism}

3-Methylbenzoate-grown cells of Pseudomonas putida $\mathrm{mt}-2$ readily converted 3 -TFM-benzoate $(5 \mathrm{mM})$ into two main 
Table 1. Relative maximum rates of dioxygenation of benzoates by 3-methylbenzoate grown cells of Pseudomonas putida mt-2

\begin{tabular}{lc}
\hline Assay substrate & $\begin{array}{l}\text { Rate of dioxygenation } \\
\text { (relative to benzoate } \\
=100 \%)\end{array}$ \\
\hline Benzoate & $100(100)^{\mathrm{b}}$ \\
2-Methylbenzoate & $9(9)$ \\
3-Methylbenzoate & $83(78)$ \\
4-Methylbenzoate & $72(63)$ \\
2-Trifluoromethylbenzoate & 0 (n.t.) \\
3-Trifluoromethylbenzoate & 12 (n.t.) \\
4-Trifluoromethylbenzoate & 3 (n.t.) \\
3,5-Di-trifluoromethylbenzoate & 0 (n.t.) \\
3-Ethylbenzoate & 30 (n.t.) \\
4-Ethylbenzoate & 23 (n.t.) \\
3,5-Dimethylbenzoate & $22(27)$ \\
3-Chlorobenzoate & n.t. (48) \\
4-Chlorobenzoate & n.t. (32) \\
3-Bromobenzoate & $31(34)$ \\
4-Bromobenzoate & $31(22)$ \\
3-Jodobenzoate & $29(39)$
\end{tabular}

a Pseudomonas putida $\mathrm{mt}-2$ was grown with 3 -methylbenzoate. Dioxygenation rates were measured by following substrate disappearance with HPLC as described in materials and methods. The optical densities of cell suspensions ranged from 2 to 15 (measured at $\lambda=546 \mathrm{~nm}$ ) depending on the reaction rates found in previously made test runs

b The values in parentheses have been published previously by other workers (Reineke and Knackmuss 1978a)

n.t. $=$ not tested

metabolites M1 and M2. Their $R_{f}$-values in solvent system I (see Materials and methods) were 0.19 and 0.4 respectively. Metabolite M2 had an intense yellow colour at $\mathrm{pH} 7.4$ becoming more intense at $\mathrm{pH} 12$ and colourless at $\mathrm{pH} 2$. These spectral shifts together with the absorption maximum at $\lambda=385 \mathrm{~nm}$ (phosphate-buffer $\mathrm{pH} 7.4 ; 50 \mathrm{mM}$ ) strongly indicated the presence of a muconate semialdehyde chromophore. Since the metabolite proved to be too unstable for direct isolation and identification it was derivatized by treatment with concentrated ammonia (Fujiwara et al. 1975).

The M2 derivative was methylated, purified by TLC and subjected to mass spectrometry and proton magnetic resonance spectroscopy. The mass spectrum (Fig. 1) corresponds to the expected structure of a TFM-picolinic acid methylester. By high resolution mass spectroscopy the parental ion $\mathrm{M}^{+}$was ascertained to have $\mathrm{m} / \mathrm{e}=205.0353$ (calculated for $\mathrm{C}_{8} \mathrm{H}_{6} \mathrm{O}_{2} \mathrm{NF}_{3}$ 205.0350). Postulating a fragmentation pattern with loss of $\mathrm{CH}_{2} \mathrm{O}$ the expected mass of $\mathrm{m} / \mathrm{e}=175.0244$ was experimentally found with $\mathrm{m} / \mathrm{e}=$ 175.0242. Loss of fluorine resulted in a signal at $\mathrm{m} / \mathrm{e}=$ 186.0366 (calculated 186.0369). Further fragments were found to have $\mathrm{m} / \mathrm{e}=147\left(\mathrm{p}-\mathrm{CH}_{2} \mathrm{O}-\mathrm{CO}\right)^{+}, 146\left(\mathrm{p}-\mathrm{CH}_{2} \mathrm{O}-\right.$ $\mathrm{CO}-\mathrm{H})^{+}, 127\left(\mathrm{p}-\mathrm{CH}_{2} \mathrm{O}-\mathrm{H}-\mathrm{F}\right)^{+}$and $126\left(\mathrm{p}-\mathrm{CH}_{2} \mathrm{O}-\mathrm{CO}-\mathrm{H}-\mathrm{F}-\right.$ $\mathrm{H})^{+}$(Stenhagen et al. 1974).

Theoretically all four isomers of TFM-2-picolinic acid can be generated from 3-TFM-benzoate (Fig. 2). In order to elucidate its actual metabolic fate in Pseudomonas putida mt-2 the position of the TFM-group in the M2-derivative had to be determined. Figure 3 shows the ${ }^{1} \mathrm{H}-\mathrm{NMR}$ spectrum of the methylester of M2 after ring closure in aqueous ammonia. Besides the three protons of the ester

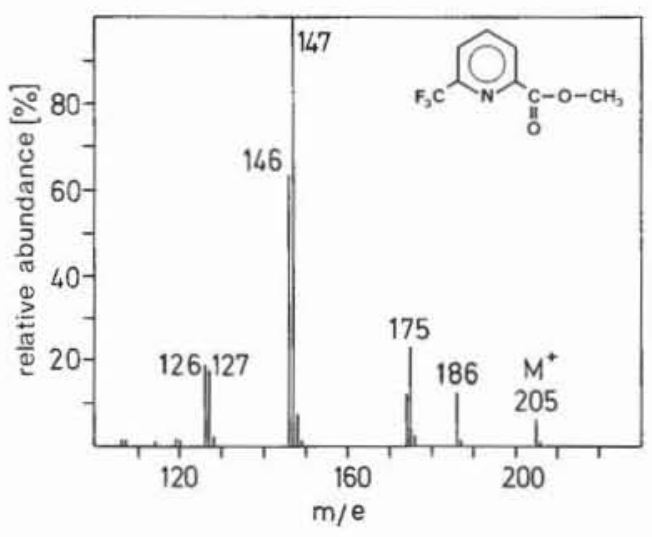

Fig. 1. The mass spectrum of derivatized metabolite M2 of cometabolism of 3-TFM-benzoate by Pseudomonas putida mt-2. The metabolite M2 was cyclized in alkaline solution of ammonia and methylated with diazomethane. Prior to mass spectrometry it was sublimed

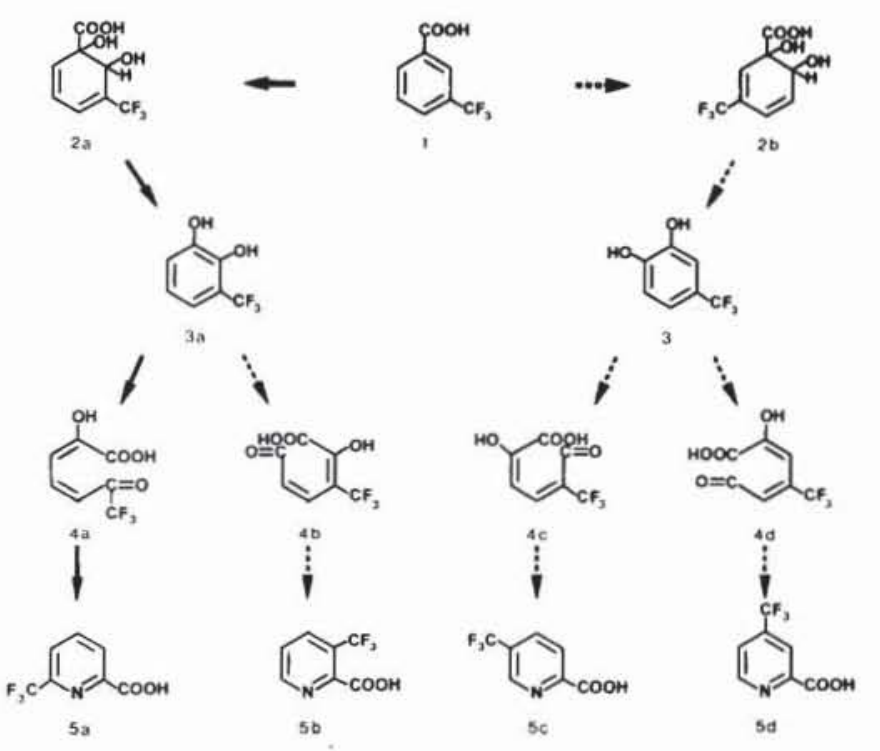

Fig. 2. Possible products of cometabolism of 3-TFM-benzoate in Pseudomonas putida mt-2. 2-Hydroxy-6-oxo-7,7,7-trifluorohepta2,4-dienoate was quantitatively derivatized (see Materials and methods) by ring closure in strongly alkaline aqueous ammonia (30\% $\mathrm{v} / \mathrm{v}$ ). The TFM-picolinic acid was then methylated using an etheral solution of diazomethane. The broken arrows denote the theoretically thinkable products $(5 b-d)$, the solid ones point at the product actually found $(5 a)$

methyl groups at $\delta \mathrm{ppm}=4(3 \mathrm{H}, \mathrm{S})$ three additional protons were encountered downfields, at about $\delta \mathrm{ppm}=8$. Proton $\mathrm{H}_{\mathrm{c}} \delta \mathrm{ppm}=7.85\left(1 \mathrm{H}, \mathrm{d}, J_{\mathrm{a}, \mathrm{b}}=8 \mathrm{~Hz}\right)$ appeared as a doublet by coupling with proton $\mathrm{H}_{\mathrm{b}} \delta \mathrm{ppm}=8.1(1 \mathrm{H}, \mathrm{t})$. Proton $\mathrm{H}_{\mathrm{c}} \delta \mathrm{ppm}=8.3\left(1 \mathrm{H}, \mathrm{d}, J_{\mathrm{a}, \mathrm{b}}=8 \mathrm{~Hz}\right)$ is split by proton $\mathrm{H}_{\mathrm{b}}$. Since both ortho-spin coupling constants are identi$\mathrm{cal}$, the theoretically expected quartet of proton $\mathrm{H}_{\mathrm{b}}$ is reduced to a simple di-ortho-triplet. The ratio of the relative peak intensities of the 'outer' protons is not $1: 1$ due to the similarity of the chemical shift of proton $\mathrm{H}_{\mathrm{a}}$ and $\mathrm{H}_{\mathrm{c}}$. Coupling constants of about $8 \mathrm{~Hz}$ are typical for ortho-protons in pyridine derivatives (Brügel 1962,1979). All these findings indicate that the three protons form a queue with no other substituents intercalating them. This coupling pattern is 
<smiles>COC(=O)c1cc(C)ccc1C(F)(F)F</smiles>

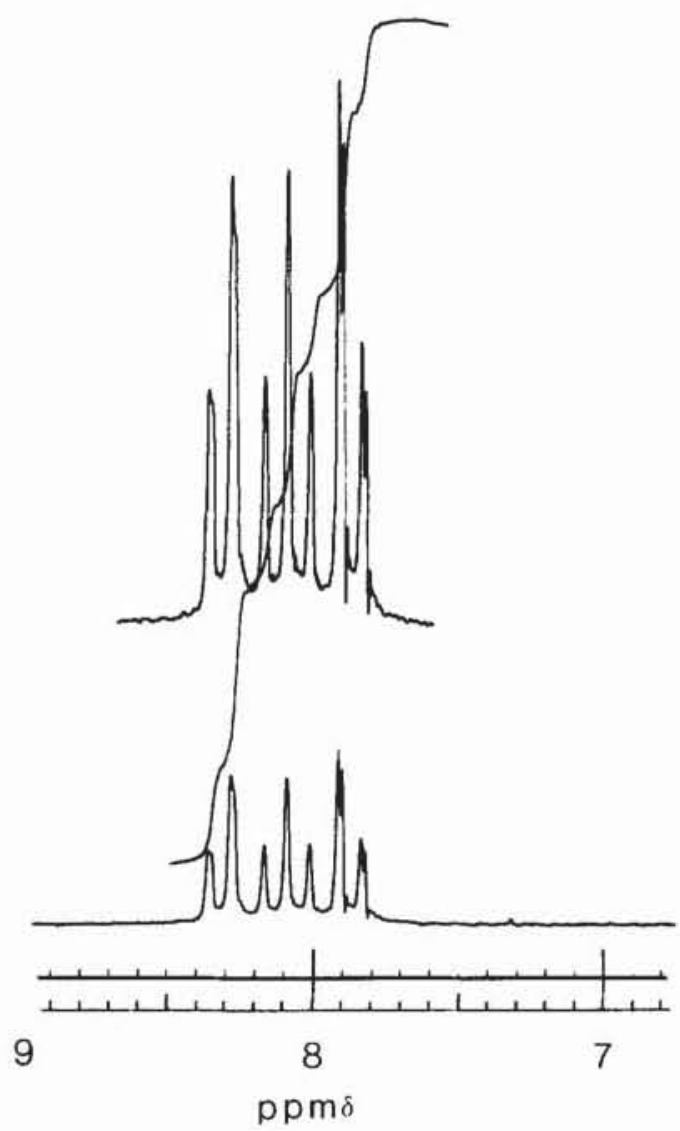

Fig. 3. ${ }^{1} \mathrm{H}-\mathrm{NMR}$ spectrum of methylester of 6-TFM-2-picolinic acid, a derivative of metabolite M2. The $100-\mathrm{MHz}$-spectrum of the compound in deuterated chloroform was recorded with tetramethylsilane (TMS) as internal standard

compatible with either the 3-isomer or the 6-isomer of trifluoromethyl-2-picolinic acid but excludes isomers $5 \mathrm{c}$ and 5 d (Fig. 2).

When the chemical shifts of aromatic protons in orthoposition to the trifluoromethyl- and methoxycarbonylgroup were compared (Brügel 1979; Kostelnik et al. 1969) it became evident that the latter function always shifted the corresponding ortho-protons considerably more downfield than the TFM-group. Furthermore protons adjacent to the pyridine-nitrogen such as those of the methylester of 2picolinic acid usually resonate at $\delta \mathrm{ppm}=8.77$. Since the lowest resonance signal of the M2-derivative centred at $\delta$ $\mathrm{ppm}=8.3$ a proton located ortho to the ring nitrogen and thus 3-TFM-2-picolinic acid could be ruled out.

Finally, hydrolysis of the TFM-group under strongly acidic conditions (see Material and methods) clearly generated 2,6-dipicolinic acid. This was confirmed by comparison with the isomers of carboxy-2-picolinic acid using HPLC and UV spectra measured in situ $\left(\lambda_{\max }=\right.$ $270 \mathrm{~nm} ; \lambda_{\min }=242 \mathrm{~nm}$ compared with authentic $2,6-$ dipicolinic acid $\lambda_{\max }=270 \mathrm{~nm}$ and $\lambda_{\min }=241 \mathrm{~nm}$ ). The IRspectra (not shown) of both samples were superimposable with the exception of a minute band at $13.5 \mu \mathrm{m}$ which was probably due to the free carboxyl group of 2,6-dipicolinic acid monoester present as a minor impurity. Obviously the muconate semialdehyde produced from 3-TFM-benzoate by Pseudomonas putida mt-2 was 2-hydroxy-6-oxo-7,7,7trifluorohepta-2,4-dienoate (7-TFHOD).

Metabolite M1 $\left(R_{f}=0.19\right.$ in solvent system I) proved to be rather unstable under acidic conditions yielding two bands on thin layer chromatography (TLC) plates (solvent system II) after it had been methylated with diazomethane. One of these bands $\left(R_{f}=0.42\right)$ was observed when the product of 3-TFM-benzoate cooxidation by Alcaligenes eutrophus B9 was similarly methylated. This mutant was blocked in the degradation pathway of benzoate and excreted 1,2-dihydroxy-2-hydrobenzoate (DHB) (Reineke and Knackmuss 1978a). Obviously M1 is a TFM-1,2-dihydroxy2-hydrobenzoate. The second band $\left(R_{f}=0.69\right)$ observed on TLC plates corresponded to a rearomatization product of TFM-1,2-dihydroxy-2-hydrobenzoate which is formed under acidic conditions. This was shown by use of high resolution mass spectrometry techniques. TFM-salicylate was identified as the main rearomatization product (parent ion $(p)^{+}$at $\left.m / e=238\right)$. Such aromatization of substituted dihydroxyhydrobenzoates have frequently been observed by other authors (Gibson et al. 1973; Wegst et al. 1981; Kunz and Chapman 1981; Reineke et al. 1978).

Further proof for the chemical structure of M1 as a TFM-1,2-dihydroxy-2-hydrobenzoate was given by IRspectra which revealed total coincidence between the methylesters of M1 and the product from cometabolism of 3-TFM-benzoate by the mutant Alcaligenes eutrophus B9 (data not shown).

For spectroscopic characterization some highly purified methylester of M1 was prepared by use of strain B9 (see Material and methods). The mass spectrum (Table 2) confirmed the structure of a TFM-1,2-dihydroxy-2-hydrobenzoate: besides the parental ion $(\mathrm{p})^{+} \mathrm{m} / \mathrm{e}=238$, typical fragmentation ions were detected at $\mathrm{m} / \mathrm{e}=220\left(\mathrm{p}-\mathrm{H}_{2} \mathrm{O}\right)^{+}$, at $\mathrm{m} / \mathrm{e}=201\left(\mathrm{p}-\mathrm{H}_{2} \mathrm{O}-\mathrm{F}\right)^{+}$and at $\mathrm{m} / \mathrm{e}=179\left(\mathrm{p}-\mathrm{COOCH}_{3}\right)^{+}$. The mass spectrum of the methyl derivative of M1 from Pseudomonas putida proved to be essentially the same as the methylated metabolite from the Alcaligenes strain (Table 2).

The positioning of the TFM-group on the cyclohexadiene-ring was determined by ${ }^{1} \mathrm{H}-\mathrm{NMR}$ spectrum of the ring protons (Fig. 4). Proton $\mathrm{H}_{\mathrm{a}}$, (attached to C-2) is attributed to the signal at $\delta \mathrm{ppm}=4.76$. This interpretation agrees with the chemical shifts of allylic protons described for other vicinal dihydrodiols. Such allylic protons resonate at highest field compared with the "vinylic" ring protons (Reineke et al. 1978; Cerniglia et al. 1979; Young et al. 1968, 1969; Laborde and Gibson 1977; DeFranc and Ribbons 1976; Jerina et al. 1971). Furthermore, this type of proton cannot couple with the other ring protons substantially $(J=$ $3.5 \mathrm{~Hz}$ ) because ring distortion diminishes the coupling constants even for ortho-located protons. Consequently, the coupling pattern of the other three ring-protons remains unaffected. The signal at $\delta \mathrm{ppm}=6.18$ can only be interpreted as proton $\mathrm{H}_{\mathrm{c}}$ split by two ortho-protons to a double ortho quartet. As vinylic coupling constants in cyclohexadiene derivatives (see Fig. 4) are in the range of $J=8.7$ to $10.7 \mathrm{~Hz}$ (Chamberlain 1974) the signals at $\delta \mathrm{ppm}=5.9$ and $\delta \mathrm{ppm}=6.5 \mathrm{can}$ be attributed to $\mathrm{H}_{\mathrm{d}}\left(J_{\mathrm{c}, \mathrm{d}}=\right.$ $10 \mathrm{~Hz})$ and $\mathrm{H}_{\mathrm{b}}$ resp. $\left(J_{\mathrm{b}, \mathrm{c}}=5.6-6 \mathrm{~Hz}\right)$. This interpretation is reinforced by the peak width of proton $\mathrm{H}_{\mathrm{b}}$ which excludes 
Table 2. Mass spectra of TEM-1,2-dihydroxy-2-hydrobenzoate, the product M1 of cometabolism of 3-TFM-benzoate by Pseudomonas putida $\mathrm{mt}-2$ and the mutant Alcaligenes eutrophus B9

\begin{tabular}{lll}
\hline $\begin{array}{l}\text { Parental ion or } \\
\text { Fragmentation products }\end{array}$ & $\begin{array}{l}\text { m/e of methylester of meta- } \\
\text { bolites from cometabolism } \\
\text { of 3-TFM-benzoate by }\end{array}$ \\
\cline { 2 - 3 } & $\begin{array}{l}\text { Pseudomonas } \\
\text { putida } \text { mt-2 } \\
\text { (metabolite M1) }\end{array}$ & $\begin{array}{l}\text { Alcaligenes } \\
\text { eutrophus } \\
\text { B9 }\end{array}$ \\
\hline$p^{+}$ & $238(10)^{\text {a }}$ & $238(10)^{b}$ \\
$p^{+}-\mathrm{H}_{2} \mathrm{O}$ & $220(15)$ & $220(13)$ \\
$\mathrm{p}^{+}-\mathrm{H}_{2} \mathrm{O}-\mathrm{F}$ & $201(7)$ & $201(8)$ \\
- & $193^{\mathrm{c}}(60)$ & - \\
$\mathrm{p}^{+}-\mathrm{COOCH}_{3}$ & $179(25)$ & $179(65)$ \\
$\mathrm{p}^{+}-\mathrm{COOCH}_{3}-\mathrm{H}$ & $178(21)$ & $178(71)$ \\
$\mathrm{p}^{+}-\mathrm{H}_{2} \mathrm{O}-\mathrm{COOCH}_{2}$ & $162(35)$ & $162(37)$ \\
$\mathrm{p}^{+}-\mathrm{H}_{2} \mathrm{O}-\mathrm{COOCH}_{3}$ & $161(100)$ & $161(94)$ \\
$\mathrm{p}^{+}-\mathrm{COOCH}_{3}-\mathrm{H}-\mathrm{CO}$ & $150(14)$ & $150(28)$ \\
$\mathrm{p}^{+}-\mathrm{COOCH}_{3}-2 \mathrm{H}-\mathrm{CO}$ & $145(25)$ & $149(27)$ \\
$\mathrm{p}^{+}-\mathrm{COOCH}_{3}-2 \mathrm{H}-2 \mathrm{CO}$ & $133(72)$ & $133(85)$ \\
$\mathrm{p}^{+}-\mathrm{COOCH}_{3}-2 \mathrm{H}-\mathrm{CO}-\mathrm{F}$ & $130(35)$ & $130(100)$ \\
\hline
\end{tabular}

$a, b$ Figures in parentheses give the relative intensities of peaks compared to $\mathrm{m} / \mathrm{e}=161$ (a) and $\mathrm{m} / \mathrm{e}=130$ (b) rsp.

c The peak at $\mathrm{m} / \mathrm{e}=193$ seems to stem from an impurity and cannot be satisfactorily explained

the possibility of an isolated proton. The signals of this proton are extensively split further by the adjacent TFMgroup $\left({ }^{1} \mathrm{H}-{ }^{19} \mathrm{~F}\right.$-long range coupling).

These data demonstrated that the metabolite from cooxidation of 3-TFM-benzoate by Alcaligenes eutrophus B9 and by Pseudomonas putida mt-2 (metabolite M1) was 3-trifluoromethyl-1,2-dihydroxy-2-hydrobenzoate. Further evidence supporting this interpretation resulted from experiments with highly purified 1,2-dihydroxy-2-hydrobenzoatedehydrogenase from Pseudomonas sp. B13 which converted M1 to 3-TFM-catechol. This compound was unstable and hydrolyzed spontaneously generating 2,3-dihydroxybenzoate (identified by HPLC). This latter observation together with other examples showing the general instability of TFM-benzene compounds substituted with vicinal hydroxyl groups will be a subject of a separate paper.

When 3-TFM-benzoate was converted into 2-hydroxy6-oxo-7,7,7-trifluorohepta-2,4-dienoate (TFHOD) and 3TFM-1,2-dihydroxy-2-hydrobenzoate relative amounts of both metabolites were 1.5:1 and no other products could be detected in the medium. Approximately $90 \%$ of the substrate was recovered as these two metabolites.

\section{Enzymatic measurements in crude extracts}

Pseudomonas putida $\mathrm{mt}-2$ harbours two sets of enzymes for the catabolism of either benzoate or 3-methylbenzoate (Nakazawa and Yokota 1973). 3-Methylbenzoate induces enzymes of the TOL-plasmid which results in meta-cleavage of catechols. Conversion of benzoates to hydrodiols and subsequent rearomatization to the corresponding catechols is catalyzed by isofunctional enzymes, coded for by genes located on the chromosome as well as on the TOL-plasmid.

Using standard heat inactivation technique 3-methylbenzoate was shown to induce almost exclusively the isoenzymes coded by the TOL-plasmid (data not shown).
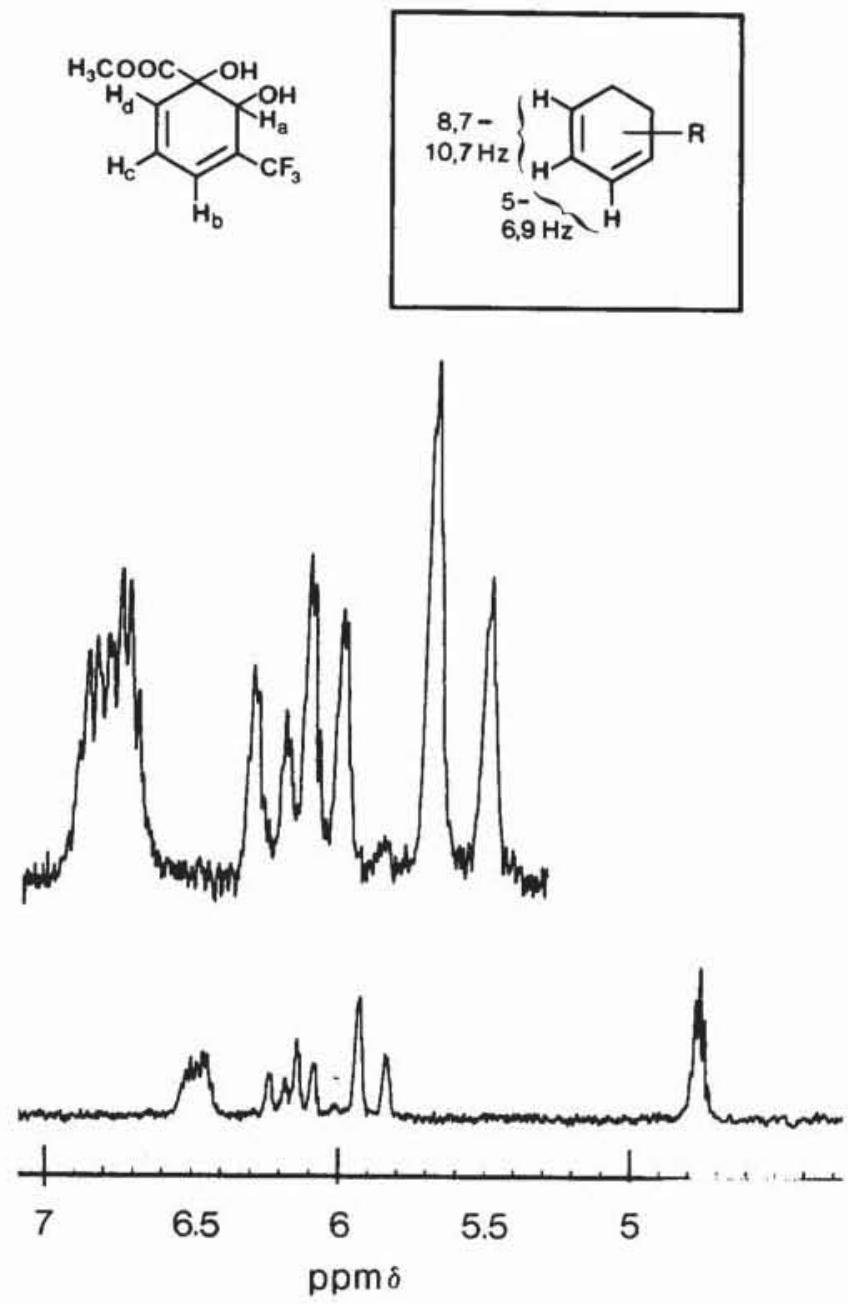

Fig. 4. ${ }^{1} \mathrm{H}-\mathrm{NMR}$-spectrum of methylester of 3-TFM-1,2-dihydro1,2-dihydroxybenzoate, a derivative of metabolite M1. The 100 $\mathrm{MHz}$-spectrum was recorded in deuterated chloroform with tetramethylsilane as internal standard. The inset shows typical coupling constants in cyclohexadiene derivatives (Chamberlain 1974)

Thus it was possible to assay the TOL-plasmid coded 1,2dihydroxy-2-hydrobenzoate (DHB)-dehydrogenase without interference from the chromosomally coded isoenzyme. The use of this mutant avoids disturbance of the assay by ring fission products of catechols. The data given in Table 3 showed that 3-TFM-1,2-dihydroxy-2-hydrobenzoate was only weakly bound to the enzyme (deduced from its $K_{\mathrm{i}^{-}}$ value) and turned over at a very low rate compared with the fluorofree compound.

For assaying the DHB-dehydrogenase in cell extracts of the wild type Pseudomonas putida $\mathrm{mt}-2$ (PaW1), a highly active metapyrocatechase was used as an auxilliary enzyme. By providing rapid meta-ring cleavage of the unstable TFMcatechols, the dehydrogenase reaction could be followed by the increase in muconate semialdehyde concentration (see Table 3). Again 3-TFM-1,2-dihydroxy-2-hydrobenzoate was poorly bound $\left(K_{\mathrm{m}}=2.86 \mathrm{mM}\right)$ compared to the fluorofree compound 3-methyl-DHB $\left(K_{\mathrm{m}}=250 \mu \mathrm{M}\right)$ and turned over very slowly $\left(V_{\max }=1 \%\right.$ referred to the fluorofree substrate $100 \%$ ).

Both poor substrate binding and low turnover rates lead to the accumulation of 3-TFM-1,2-dihydroxy-2-hydro- 
Table 3. Michaelis constants and relative maximum turnover velocities of 1,2-dihydroxy-2-hydrobenzoate(DHB)-dehydrogenases from Pseudomonas putida $\mathrm{mt}-2$ and Rhodococcus rubropertinctus N657

\begin{tabular}{|c|c|c|c|c|}
\hline \multirow[t]{2}{*}{$\begin{array}{l}\text { Assay } \\
\text { substrate }\end{array}$} & \multicolumn{2}{|c|}{$\begin{array}{l}\text { Pseudomonas putida } \mathrm{mt}-2 \\
\text { (PaW 258) }^{\mathrm{b}}\end{array}$} & \multicolumn{2}{|c|}{$\begin{array}{l}\text { Rhodococcus rubro- } \\
\text { pertinctus } \mathrm{N} 657^{\circ}\end{array}$} \\
\hline & $\begin{array}{l}K_{\mathrm{m}} \\
{[\mu \mathrm{M}]}\end{array}$ & $\begin{array}{l}\text { rel. } V_{\max } \\
{[\%]}\end{array}$ & $\begin{array}{l}K_{\mathrm{m}} \\
{[\mu \mathrm{M}]}\end{array}$ & $\begin{array}{l}\text { rel. } V_{\max } \\
{[\%]}\end{array}$ \\
\hline $\begin{array}{l}\text { 1,2-Dihydroxy- } \\
\text { 2-hydrobenzoate } \\
\text { (DHB) }\end{array}$ & 330 & 100 & 200 & 100 \\
\hline 3-Methyl-DHB & $130(250)^{\mathrm{a}}$ & $110(100)^{\mathbf{a}}$ & 150 & 80 \\
\hline $\begin{array}{l}\text { 3-Trifluoro- } \\
\text { methyl-DHB }\end{array}$ & $\begin{array}{l}K_{\mathrm{i}}=2600 \\
(2900)^{\mathrm{a}}\end{array}$ & $\begin{array}{c}1 \\
(1)^{\mathrm{a}}\end{array}$ & 370 & 3 \\
\hline 3-Fluoro-DHB & 400 & 40 & 550 & 70 \\
\hline 3-Chloro-DHB & 250 & 90 & 160 & 82 \\
\hline 3-Bromo-DHB & 150 & 100 & 70 & 68 \\
\hline
\end{tabular}

The enzymes were assayed following the increase of absorbance of $\mathrm{NADH}$ in $50 \mathrm{mM}$ phosphate buffer. The NAD ${ }^{+}$concentration was kept constant at $2 \mathrm{mM}$. Michaelis constants were calculated from Lineweaver-Burk plots. $K_{\mathrm{i}}$-values were determined from a replot showing the dependence of slope of Lineweaver-Burk plots from different constant concentrations of the inhibitor 3-TFM-1,2dihydroxy-2-hydrobenzoate added to the assay mixture. The crude extracts were dialyzed for $24 \mathrm{~h}$ against $50 \mathrm{mM}$ phosphate-buffer $(\mathrm{pH} 7.4)$ after centrifugation at $100,000 \times g(1 \mathrm{~h})$

a The $K_{\mathrm{m}}$ - and the $K_{\mathrm{i}}$ - as well as the $V_{\max }$-values in parentheses were obtained using 3-methylbenzoate grown cells of wild type Pseudomonas putida $\mathrm{mt}-2$. Turnover of 3-TFM-1,2-dihydroxy-2hydrobenzoate was assayed by following the increase in absorbance of 2-hydroxy-6-oxo-7,7,7-trifluorohepta-2,4-dienoate. This compound is produced by the very active auxilliary enzyme catechol2,3-dioxygenase and is not transformed further

b Pseudomonas putida $\mathrm{mt}-2$ ( $\mathrm{PaW} 258$ ) is a mutant defective in catechol-2,3-dioxygenase and was grown in succinate and induced with 4-methylbenzoate ( $2 \mathrm{mM}$ )

- Rhodococcus rubropertinctus was grown with 4-methylbenzoate

benzoate during cometabolism of 3-TFM-benzoate by Pseudomonas putida $\mathrm{mt}-2$. In contrast, the hydrodiol-dehydrogenase from Rhodococcus rubropertinctus N657 showed normal binding behaviour with 3-TFM-1,2-dihydroxy-2hydrobenzoate (Table 3 ), which agreed well with the absence of excretion of this product during 3-TFM-benzoate cometabolism by this organism. Turnover rates, however, were severely slowed down as shown above with the $P$ seudomonas enzyme. Growth of Pseudomonas putida $\mathrm{mt}-2$ with 3 -methylbenzoate gave rise to induction preponderantly of the meta-cleaving catechol-2,3-dioxygenase (metapyrocatechase) which generates muconate semialdehydes from catechols (Nakazawa and Yokota 1973; Williams and Murray 1974). This enzyme could be assayed simply by heating dialyzed extracts to $55^{\circ} \mathrm{C}$ thereby destroying the subsequent enzyme, semialdehyde-hydrolase. It bound 3TFM-catechol comparably to the reference substrate 3methylcatechol (Table 4) as revealed by their $K_{\mathrm{m}}$ - and $K_{\mathrm{i}}$ values. Inhibition of 3-methylcatechol turnover by the fluorine-containing substrate was of the competitive type. The turnover rate of 3-TFM-catechol was relatively high demonstrating only a moderate influence of side chain fluoro-substitution on meta-cleavage in Pseudomonas putida $\mathrm{mt}-2$.
Table 4. Relative maximum turnover rates of catechol-1,2 dioxygenase from Rhodococcus rubropertinctus $\mathrm{N} 657^{\mathrm{a}}$ and catechol2,3-dioxygenase from Pseudomonas putida $\mathrm{mt}-2^{\mathrm{b}}$

\begin{tabular}{|c|c|c|c|c|}
\hline \multirow[t]{2}{*}{ Substrate } & \multicolumn{2}{|c|}{$\begin{array}{l}\text { Catechol-1,2- } \\
\text { dioxygenase }^{c} \\
\text { (Rhodococcus) }\end{array}$} & \multicolumn{2}{|c|}{$\begin{array}{l}\text { Catechol-2,3- } \\
\text { dioxygenase }^{f} \\
\text { (Pseudomonas) }\end{array}$} \\
\hline & $\begin{array}{l}K_{\mathrm{m}} \\
{[\mu \mathrm{M}]^{\mathrm{d}}}\end{array}$ & $\begin{array}{l}V_{\operatorname{maxrel}} \\
{[\%]}\end{array}$ & $\begin{array}{l}K_{\mathrm{m}} \\
{[\mu \mathrm{M}]^{\mathrm{d}}}\end{array}$ & $\begin{array}{l}V_{\operatorname{maxrel}} \\
{[\%]}\end{array}$ \\
\hline Catechol & 1.5 & $100(100)$ & n.d. ${ }^{g}$ & n.d. \\
\hline 3-Methylcatechol & 2.5 & $75(11)$ & 2 & 100 \\
\hline $\begin{array}{l}\text { 3-Trifluoromethyl- } \\
\text { catechol }\end{array}$ & $K_{\mathrm{i}}=0.02$ & $\begin{array}{r}0.3^{\mathrm{e}} \\
\text { (n.d.) })^{\mathrm{g}}\end{array}$ & $\begin{array}{c}2.5 \\
\left(K_{\mathrm{i}}=2.1\right)\end{array}$ & 8 \\
\hline 4-Methylcatechol & 3.8 & $83(92)$ & n.d. & n.d. \\
\hline 3-Chlorocatechol & n.d. & $1.5(0,7)$ & $K_{\mathrm{i}}=23$ & $1 \mathrm{~h}$ \\
\hline 4-Chlorocatechol & n.d. & $4(11)$ & n.d. & 78 \\
\hline 3-Fluorocatechol & n.d. & $0.7(0.4)$ & $K_{\mathrm{i}}=17$ & $5^{\mathrm{h}}$ \\
\hline 4-Fluorocatechol & 2.7 & $72(30)$ & n.d. & 68 \\
\hline $\begin{array}{l}\text { 3-Isopropyl- } \\
\text { catechol }\end{array}$ & 52 & $10^{e}$ (n.d.) & 160 & $54^{\mathrm{h}}$ \\
\hline 3-Methoxycatechol & n.d. & 4 (n.d.) & 18 & 133 \\
\hline
\end{tabular}

${ }^{2}$ Rhodococcus rubropertinctus was grown with 4-methylbenzoate

b Pseudomonas putida $\mathrm{mt}-2$ was grown with 3-methylbenzoate

- Catechol-1,2-dioxygenase was assayed by following the increase of absorption of muconic acids (Dorn and Knackmuss 1978). The value of catechol was taken to be $100 \%$. The values in parentheses were estimated with a catechol-1,2-dioxygenase of benzoate grown Pseudomonas sp. B13 (Dorn and Knackmuss 1978) and are given for comparison

d $K_{\mathrm{m}}$ - and $K_{\mathrm{i}}$-values were determined by a replot of slopes of Lineweaver-Burk plots, which had been inhibited by different constant concentrations of 3-trifluoromethylcatechol against inhibitor concentrations

- An extinction coefficient of $\varepsilon=15.000$ was assumed

f Catechol 2,3-dioxygenase was assayed spectrophotometrically using an oxygen electrode. Extinction coefficients, it not described in Material and methods, were derived from literature (Murray et al. 1972; Fujiwara et al. 1975; Nakazawa and Yokota 1973; Williams and Murray (1974) as were the $K_{\mathrm{i}}$-values of fluoro- and chlorocatechol (Bartels et al. 1984)

s n.d. $=$ not determined

b Reaction rate was extrapolated due to inactivation of the enzyme

Catechol-1,2-dioxygenase from Rhodococcus rubropertinctus N657, however, bound 3-TFM-catechol extremely tightly, although the conversion of this substrate was very slow. Similarly, ring cleavage of 3-chlorocatechol proceeds very slowly although inhibition experiments (catechol and TFM catechol at $33 \mu \mathrm{M}$ each) indicate high affinity. Whereas the TFM-group as a substituent reduced turnover of catechol to $4 \%$ of the velocity in the absence of inhibitor, dioxygenation rate in the presence of 3-chlorocatechol was reduced to only $11 \%$. In contrast, 3 -methylcatechol showed only moderate binding capacity to the enzyme but high turnover rates.

The HOD-hydrolase in Pseudomonas putida $\mathrm{mt}-2$ converted 2-hydroxy-6-oxo-2,4-heptadienoate (HOD) to acetate and 2-oxo-penta-2,4-dienoate, an unusual reaction type of C-C-bond-cleavage. Substitution of hydrogen atoms of the terminal methyl group of HOD by fluorine sharply increased its affinity for the enzyme $\left(K_{\mathrm{i}}=300 \mathrm{nM}\right.$ for 2-hydroxy-6-oxo-7,7,7-trifluoro-hepta-2,4-dienoate, TFHOD, compared to $K_{\mathrm{m}}$-value of $\mathrm{HOD}=8 \mu \mathrm{M}$ ). The 


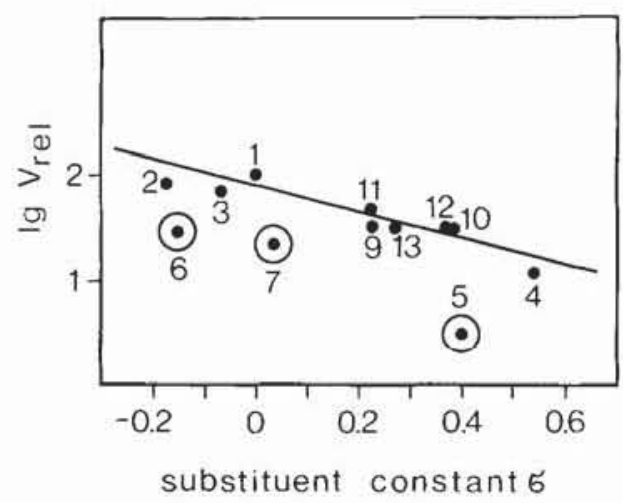

Fig. 5. Correlation between $\log V_{\max }$-values of the toluate dioxygenase reaction in Pseudomonas putida mt-2 with substituted benzoates and the corresponding substituent constants. The $V_{\max }$ values are listed in Table 1 . The corresponding substituent constants $\sigma$ are adopted from literature (Reineke and Knackmuss 1978a; Norman and Taylor 1965). The circles around the symboles of substrate 5, 6 and 7 indicate that they have not been considered for approximation of the graph. The numbers stand for: 1 benzoate; 2 3-methylbenzoate; 3 4-methylbenzoate; 4 3-TFM-benzoate; 5 4-TFM-benzoate; 6 3-ethylbenzoate; 7 4-ethylbenzoate; 9 3-bromobenzoate; 10 4-bromobenzoate; 11 3-chlorobenzoate; 12 4-chlorobenzoate; 13 3-iodobenzoate

turnover rate, however, was drastically reduced by fluorine substitution to values below $0.1 \%$ of HOD. The inhibition of HOD turnover by TFHOD was of competitive type. That TFHOD was not a substrate of HOD hydrolase cannot be explained in terms of simple steric constraints; 7,7-dimethylHOD, where two hydrogens of HOD are replaced by methyl substituents, was still significantly converted by this enzyme ( $V_{\text {rel }}=7 \%$ compared with HOD), even though the resulting terminal group was much bulkier than that of TFHOD. Similar substituent effects have been obtained with enzyme preparations from cymene (4-isopropylbenzoate) degrading strains (Engesser et al. 1988).

\section{Discussion}

Fluorine is an exceptional element within the halogen group. With respect to its size it is closer to hydrogen than to the other halogens (Sheppard and Sharts 1969). Because of its strong electronegativity, however, fluorine unlike hydrogen polarizes its bond to carbon giving it a semi-ionic character (Walsh 1983). Thus trifluoroacetic acid is about $10^{5}$ times more acidic than acetic acid itself (Chambers 1973). The strong electron-withdrawing effect of the trifluoromethyl (TFM)-group was revealed also by nucleophilic substitution of TFM-heteroaromatics (Kobayashi and Kumadaki 1977).

The fact that many enzymes cannot distinguish fluorinated analogues from their unsubstituted counterparts frequently leads to extensive metabolism of the fluoro compound along preexistent metabolic routes. The metabolism may terminate if a reaction step which is highly sensitive to inductive and mesomeric effects of the fluorine substituent is reached.

A well-known example is fluoroacetate poissoning in organisms with an operating Krebs cycle (Walsh 1983) where fluorocitrate, formed from fluoroacetate, blocks the aconitase enzyme. Another example of lethal synthesis was found when the cometabolism of 3-halobenzoates by 3 methylbenzoate grown cells of Pseudomonas putida mt-2

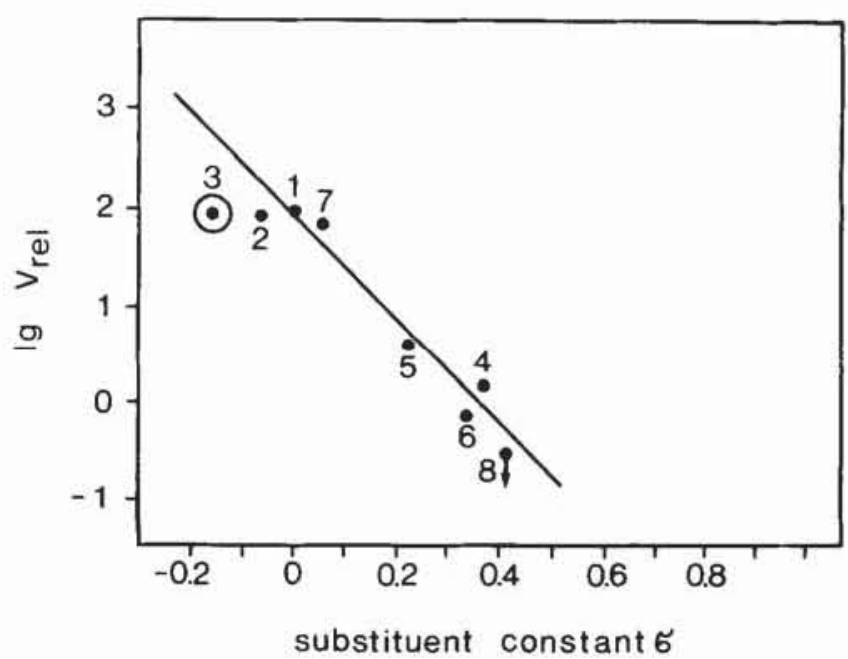

Fig. 6. Correlation of $\lg V_{\max }$-values of catechol-1,2-dioxygenase reaction in Rhodococcus rubropertinctus N657 with substituted catechols and the substituent constants. The $V_{\max }$-values are listed in Table 4. The substituent constants $\sigma$ are adopted from literature (Dorn and Knackmuss 1978; Norman and Taylor 1965). The numbers stand for: 1 catechol; 2 3-methylcatechol; 3 4-methylcatechol; 4 3-chlorocatechol; 5 4-chlorocatechol; 6 3-fluorocatechol; 7 4-fluorocatechol; 8 3-TFM-catechol. Substrate 3 was not considered for formation of the graph

was studied. 3-Fluorocatechol, when split by a catechol2,3-dioxygenase led to suicide inactivation of this enzyme thereby blocking growth on methylbenzoate (Bartels et al. 1984).

An investigation of fumarate hydratase revealed that substituted fumarates all were hydrated to form 3-substituted malates. Fluorofumarate, however, was hydrated selectively at the fluorine-bearing carbon atom generating a highly unstable product, 2-fluoromalate, which spontaneously decomposed into fluoride and oxaloacetate (Teipel et al. 1968).

During this study it became clear that the nature as well as the intensity of the influence of side-chain fluorination on bacterial metabolism of toluates varied extensively. Side chain fluorination only slightly modified the selectivity of toluate dioxygenation by Pseudomonas putida mt-2. According to a previously established (Reineke and Knackmuss 1978 a) but later questioned (Schmidt and Knackmuss 1984) rule, the increasing size of substituents in 3-substituted benzoates should increase the product ratio of 3- to 5-substituted 1,2-dihydroxy-2-hydrobenzoates. With 3-methylbenzoate as a substrate the yield of the 3-methyl-isomer was found to be $90 \%$; according to the rule 3-TFM-benzoate generated the pure 3-isomer without any detectable amounts of the 5-isomer. Reaction rates of toluate dioxygenase as well as substrate binding, however, were strongly reduced if side chain fluorinated toluates were used as substrates. If log $V_{\text {rel }}$ values from Table 1 were plotted against the substituent constants $\sigma$, the value of 3-TFM-benzoate fulfilled the Hammett-equation (Fig. 5) quite well. Thus, the strong electron-withdrawing effect of the TFM-group lowered the electron density of the aromatic nucleus and thereby impeded the electrophilic attack (Reineke and Knackmuss 1978 a) of oxygen. The sensitivity of the reaction was quite low $(\varrho=-1.29)$. The high steric constraints of the enzyme were indicated by the dioxygenation rates of 3- and 4ethylbenzoate being relatively much lower. This was true 


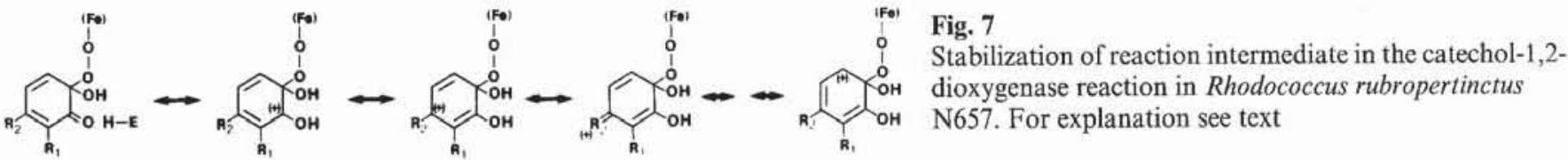

also for 4-TFM-benzoate showing that fluorine side chain substitution sometimes had a significant impact in steric terms.

Insufficient binding of 3-TFM-benzoate by toluate dioxygenase cannot be attributed just to steric effects. This was demonstrated by the normal binding (Reineke and Knackmuss 1978a) of 3-methyl- and particularly of 3iodobenzoate, where the iodo substituent required approximately the same space as the TFM-group. Obviously, the polarity of this group rendered 3-TFM-benzoate unable to inhibit benzoate turnover.

3-TFM-1,2-dihydroxy-2-hydrobenzoate formed from 3TFM-benzoate by toluate dioxygenase was poorly bound to 1,2-dihydroxy-2-hydrobenzoate-(DHB)dehydrogenase of Pseudomonas putida mt-2. Since 3-methyl-DHB as well as 3fluoro-DHB were readily bound by this enzyme (Table 3 ), poor binding of 3-TFM-DHB can neither be explained in simple steric terms nor can the acidifying influence of C-3substituents alone be the reason. Obviously, both bulkiness and polarity of substituents interfere with substrate binding to DHB-dehydrogenase. The same argument holds for the DHB-dehydrogenases of Pseudomonas sp. B13 and an Alcaligenes eutrophus strain where 4-chloro-DHB is poorly bound, whereas the bulky 4-methyl-DHB and polar but small 4-fluoro-DHB showed lower Michaelis constants (Reineke and Knackmuss 1978b).

In the reaction mechanism of DHB-dehydrogenase (Reineke and Knackmuss 1978b), NAD ${ }^{+}$is believed to accept a hydride ion attached to $\mathrm{C}-2$ of $\mathrm{DHB}$ with accompanying ketonization of the geminal hyroxyl group. This transiently-formed ketone rearomatizes chemically with concomitant decarboxylation.

The DHB-dehydrogenase from Pseudomonas sp. B13 transformed 3-substituted DHB's regardless of the electronic character of the substituent (Reineke and Knackmuss 1978 b). Similar dehydrogenation rates of substituted benzyl alcohols (Hardman et al. 1974) and primary alcohols (Blackwell and Hardman 1975) also reveal only moderate substituent effects. This indicates the generation of a small amount of positive charge in the rate-determining step of hydride transfer i.e. dehydrogenation and ketonization seem to be synchronized (Fersht 1985). Accordingly, DHBdehydrogenases from methylbenzoate-grown Pseudomonas putida $\mathrm{mt}-2$ and Rhodococcus rubropertinctus $\mathrm{N} 657$ also do not show any substantial substituent effect during dehydrogenation reaction of 3-substituted DHB's (Table 3) with the exception of 3-TFM-1,2-dihydroxy-2hydrobenzoate which is poorly attacked. As this is not due to the electronic influence of the TFM-group, a stereo-chemical explanation has to be considered. As a consequence of the nonplanarity of the cyclohexadiene ring of optically active DHB's, every stereoisomer has two conformational options, which according to Dreiding models differ markedly in structural respects. Either by hydrogen bonding or by repulsion, the TFM-group could substantially influence catalysis by stabilizing a 'wrong' isomer, which may not be transformed. This effect of fluorine has recently been demonstrated (Thakker et al. 1984) for the metabolism of fluorinated benzpyrene-7,8-dihydrodiols.

The influence of the TFM-group on the ring cleavage of 3-TFM-catechol was studied by choosing a catechol2,3-dioxygenase (meta-pyrocatechase) from Pseudomonas putida mt-2 and a catechol-1,2-dioxygenase (ortho-pyrocatechase) from Rhodococcus rubropertinctus N657 (Table 4). 3TFM-catechol showed good binding behaviour to metapyrocatechase and a moderate turnover rate compared to the natural substrate 3-methylcatechol. Thus, no 3-TFMcatechol was excreted during cometabolism of 3-TFMbenzoate by Pseudomonas putida mt-2. The orthopyrocatechase of Rhodococcus sp., however, showed no substantial turnover with 3-TFM catechol, although this substrate was strongly bound as shown by its inhibition potential (Table 4). Similarly 3-chlorocatechol was readily bound but hardly cleaved by this enzyme. The improvement of substrate binding by electronegative substituents was reported also for catechol 1,2-dioxygenases from Pseudomonas sp. B13 (Dorn and Knackmuss 1978).

With respect to its catalytic performance, the catechol 1,2-dioxygenase from Rhodococcus rubropertinctus N657, (in sharp contrast to the metapyrocatechase from Pseudomonas putida mt-2) showed a good correlation between turnover rates of substituted catechols and the corresponding substituent constants (Fig. 6). Only the value of 4-methylcatechol did not follow the Hammett equation indicating some steric hindrance. The sensitivity of the reaction was high $(\varrho=-5.5)$. These kinetic data can be interpreted by adopting a reaction mechanism which was proposed for a chlorocatechol-splitting 1,2-dioxygenase (Dorn and Knackmuss 1978). Accordingly the initial steps would obey the rules of an electrophilic aromatic substitution reaction. The stabilization of the intermediate generated after attack by an enzyme-bound dioxygen species therefore would be ratelimiting (Fig. 7). Due to their negative inductive effect, substituents like halogen and TFM would exert a destabilizing influence on the intermediate and thus impede this ratelimiting step. In the case of 4-fluorocatechol $\left(R_{2}=\mathrm{F}\right.$; Fig. 7) the negative inductive effect is superimposed on a strong mesomeric effect which explains the unusually high activity towards this substrate. Thus, the very low turnover rate for 3-TFM-catechol by the Rhodococcus ortho-pyrocatechase fits nicely in the now well established theory that it is the electronegative effect of substituents which retards cleavage reaction of catechols.

With regard to the meta-pyrocatechase of Pseudomonas putida $\mathrm{mt}-2$, however, the rate-limiting step of dioxygenation could be acyl migration of the 2-hydroperoxide ketone to a seven membered anhydride (Saeki et al. 1980). This step was shown to be in some cases also dependent on electron density at the peroxide bearing C-atom i.e. carbon atom 3 of 3substituted catechols (Walsh et al. 1983). Accordingly, the TFM-group and other electron-withdrawing substituents could exert a negative influence only when attached to C-3, but not to C-4 of the catechol moiety. This is reflected by the good turnover of 4-fluoro- and 4-chlorocatechol. 
In sharp contrast to the meta-pyrocatechase reaction the subsequent catabolic step of hydrolysis of 2-hydroxy-6-oxo7,7,7-trifluorohepta-2,4-dienoate (7-TFHOD) to trifluoroacetate and 2-hydroxy-penta-2,4-dienoate proceeded extremely slowly. The reason for this will be analyzed in a subsequent paper on 4-TFM-benzoic acid catabolism by cymene degrading bacteria (Engesser et al. 1988).

Acknowledgements. We would like to thank M.A. Rubio for many helpful discussions. We gratefully acknowledge the following for spectral and analytical services: G. Remberg and U. Leonhard, Universität Göttingen, Göttingen, FRG, for mass spectrometry and NMR spectrometry. This work was supported, in part by the Gesellschaft für Strahlen- und Umweltforschung, Neuherberg/ München, FRG.

\section{References}

Bartels J, Knackmuss HJ, Reineke W (1984) Suicide inactivation of catechol-2,3-dioxygenase from Pseudomonas putida $\mathrm{mt}-2$ by 3halocatechols. Appl Environ Microbiol 47:500-505

Blackwell LF, Hardman MJ (1975) Effect of substrate structure on the pre-steady-state kinetics of oxidation by liver alcohol dehydrogenase. Eur J Biochem 55:611-615

Brilon C, Beckmann W, Knackmuss HJ (1981) Metabolism of naphthalenesulfonic acids by Pseudomonas sp. A3 and Pseudomonas sp. C22. Appl Environ Microbiol 1:44-55

Brügel W (1962) Die Kernresonanzspektren von Pyridin-Derivaten. Z Elektrochem 66:168-174

Brügel W (1979) Handbook of NMR spectral parameters, vol 2. Heyden, London, pp 561-578

Buist PH, Findlay IM (1984) Fluorine substituent effects of biomethylenation of olefinic fatty acids. Tetrahedr Letts 14:14331436

Cerniglia CE, Morgan JC, Gibson PT (1979) Bacterial and fungal oxidation of dibenzofuran. Biochem J 180:175-185

Chamberlain NF (1974) The practice of NMR-spectroscopy. Plenum Press, New York, p 304

Chambers RO (1973) Fluorine in organic chemistry. Wiley, New York

Dagley S (1984) Pathways for the utilization of organic growth substrates. In: Gunsalus LC (ed) The bacteria, chapt 5: Bacterial diversity, vol 6. Academic Press, New York, pp 305-388

DeFranc JJ, Ribbons DW (1976) The p-cymene-pathway in Pseudomonas putida $\mathrm{PL}$ : isolation of a dihydrodiol accumulated by a mutant. Biochem Biophys Res Commun 70:1129-1135

Dorn E, Knackmuss HJ (1978) Chemical structure and biodegradability of halogenated aromatic compounds: substituent effects on 1,2-dioxygenation of catechol. Biochem J 174:8594

Dorn E, Hellwig M, Reineke W, Knackmuss HJ (1974) Isolation and characterization of a 3-chlorobenzoate degrading pseudomonad. Arch Microbiol 99:61-70

Engesser KH, Schmidt E, Knackmuss HJ (1980) Adaptation of Alcaligenes eutrophus B9 and Pseudomonas sp. B13 to 2-fluorobenzoate as growth substrate. Appl Environ Microbiol 39:68 73

Engesser KH, Rubio MA, Ribbons DW (1988) Bacterial metabolism of side chain fluorinated aromatics: cometabolism of 4-trifluoromethyl(TFM)-benzoate by 4-isopropylbenzoate grown Pseudomonas putida JT strains. Arch Microbiol 149:198-206

Fersht A (1985) Enzyme, structure and mechanism. Freeman, New York, p 404

Fujiwara M, Golovleva LA, Saeki Y, Nozaki M, Hayaishi O (1975) Extradiol cleavage of 3 -substituted catechols by an intradio dioxygenase, pyrocatechase, from a pseudomonad. J Biol Chem $13: 4848-4855$

Gibson DT (1971) The microbial oxidation of aromatic hydrocarbons. Crit Rev Microbiol 1:199-223
Gibson DT, Roberts RL, Wells MC, Kobal VM (1973) Oxidation of biphenyl by a Beijerinckia species. Biochem Biophys Res Commun 50:211-219

Goodfellow M, Minnikin DE (1984) A critical evaluation of Nocardia and related taxa. In: Ortiz-Ortiz L, Bojalil LF, Yakoleff V (eds) Biological, biochemical and biomedical aspects of actinomycetes. Academic Press, New York, pp 583-596

Grady CPL (1985) Biodegradation: Its measurement and microbiological basis. Biotechnol, Bioengen 27:660-674

Hardman MJ, Blackwell LF, Boswell CR, Buckley PD (1974) Substituent effects on the pre-steady state kinetics of oxidation of benzylalcohols by liver alcohol dehydrogenase. Eur J Biochem $50: 113-118$

Hartmann J, Reineke W, Knackmuss HJ (1979) Metabolism of 3-chloro-, 4-chloro- and 3,5-dichlorobenzoate by a pseudomonad. Appl Environ Microbiol 37:421 -428

Jerina DM, Daly JW, Jeffrey AM, Gibson DT (1971) Cis-1,2 dihydroxy-1,2-dihydronaphthalene: a bacterial metabolite from naphthalene. Arch Biochem Biophys 142:394-396

Kobayashi Y, Kumadaki J (1977) Reactions of aromatic trifluoromethyl compounds with nucleophilic reagents. Acc Chem Res 11:197-204

Kostelnik RJ, Williamson MP, Wisnosky DE, Castellano SM (1969) Nuclear magnetic resonance spectral parameters of $\alpha, \alpha, \alpha$ trifluorotoluene. Can J Chem 47:3313-3318

Kunz DA, Chapman PJ (1981) Catabolism of pseudocumene and 3 -ethyltoluene by Pseudomonas putida (arvilla) $\mathrm{mt}-2$. Evidence for new functions of the TOL (pWWO) plasmid. J Bacteriol 146:179-191

Laborde AL, Gibson DT (1977) Metabolism of dibenzothiophene by a Beijerinckia species. Appl Environ Microbiol 34:783-790

Maier EJ, Fritschi G, Kussmaul H (1978) Identifizierung von Fluorkohlenwasserstoffen im Main mittels Gaschromatographie-Massenspektrometrie. Vom Wasser 51:227-234

Miller DJ (1981) Toluate metabolism in nocardioform actinomycetes: utilization of the enzymes of the 3-oxoadipate pathway for the degradation of methyl-substituted analogues. In: Schaal KP, Pulverer G (eds) Actinomycetes, Zbl Bakt Suppl 11. Fischer, Stuttgart New York, pp 355-360

Murray K, Duggleby CJ, Sala-Trepat JMS, Williams PA (1972) The metabolism of benzoate and methylbenzoate via the meta cleavage pathway by Pseudomonas arvilla $\mathrm{mt}-2$. Eur J Biochem $28: 301-310$

Nakazawa T, Yokota T (1973) Benzoate metabolism in Pseudomonas putida (arvilla) mt-2: demonstration of two benzoate pathways. J Bacteriol 115:262-267

Norman ROC, Taylor R (1965) Electrophilic substitution in benzenoid compounds. Elsevier, Amsterdam

Reineke W (1984) Microbial degradation of halogenated aromatic compounds. In: Gibson DT (ed) Microbial degradation of organic compounds, vol 13. Marcel Dekker, New York, pp 319-360

Reineke W, Knackmuss HJ (1978a) Chemical structure and biodegradability of halogenated aromatic compounds. Substituent effects on 1,2-dioxygenation of benzoic acids. Biochim Biophys Acta 542:412-423

Reineke W, Knackmuss HJ (1978b) Chemical structure and biodegradability of halogenated compounds. Substituent effects on dehydrogenation of 3,5-cyclohexadiene-1,2-diol-1carboxylic acid. Biochem Biophys Acta 542:424-429

Reineke W, Jeenes DJ, Williams PA, Knackmuss HJ (1982) TOL plasmid pWWO in constructed halobenzoate-degrading Pseudomonas strains: prevention of meta pathway. J Bacteriol 150:195-201

Reineke W, Otting W, Knackmuss HJ (1978) cis-Dihydrodiols microbially produced from halo- and methylbenzoic acids Tetrahedron 34:1701 - 1708

Saeki Y, Nozaki M, Senoh S (1980) Cleavage of pyrogallol by nonheme iron containing dioxygenases. J Biol Chem 255:84658471

Schmidt E, Knackmuss HJ (1980) Chemical structure and biodegradability of halogenated aromatic compounds: conversion 
of chlorinated muconic acids into maleoylacetic acid. Biochem J 192:339-347

Schmidt E, Knackmuss HJ (1984) Production of cis,cis-muconate from benzoate and 2-fluoro-cis,cis-muconate from 3-fluorobenzoate by 3 -chlorobenzoate degrading bacteria. Appl Microbiol Biotechnol 20:351-355

Schmidt E, Remberg G, Knackmuss HJ (1980) Chemical structure and biodegradability of halogenated aromatic compounds: halogenated muconic acids as intermediates. Biochem J $192: 331-337$

Schreiber A, Hellwig M, Dorn E, Reineke W, Knackmuss HJ (1980) Critical reactions in fluorobenzoic acid degradation by Pseudomonas sp. B13. Appl Environ Microbiol 39:58-67

Sheppard WA, Sharts CM (1969) Organic fluorine chemistry. The trifluoromethyl group. Benjamin, New York, pp 410-411

Stenhagen E, Abrahamsson S, Mc Lafferty FW (1974) Registry of mass spectral data, vol 2. Wiley, New York, p 937

Teipel JW, Hass GM, Hill RL (1968) The substrate specificity of fumarase. J Biol Chem 21:5684-5694

Thakker DR, Yagi H, Sayer JM, Kapur U, Levin W, Chang RL, Wood AW, Conney AH, Jerina DM (1984) Effects of 6-fluoro substituent on the metabolism of benzo(a)pyrene 7,8-dihydrodiol to bay-region diol epoxides by rat liver enzymes. J Biol Chem 18:11249-11256

Tsukamura M (1982) Numerical analysis of the taxonomy of Nocardiae and Rhodococci. Microbiol Immunol 12:11011119
Walsh C (1983) Fluorinated substrate analogs: routes of metabolism and selective toxicity. Adv Enzymol 55:197-289

Walsh TA, Ballou DP, Mayer R, Que jr L (1983) Rapid reaction studies on the oxygenation reactions of catechol dioxygenase. $\mathrm{J}$ Biol Chem 258:14422-14427

Wegst W, Tittmann V, Eberspächer J, Lingens F (1981) Bacterial conversion of phenylalanine and aromatic carboxylic acids into dihydrodiols. Biochem J 194:679-689

Williams PA, Murray K (1974) Metabolism of benzoate and the methylbenzoates by Pseudomonas putida (arvilla) mt-2. Evidence for the existence of a TOL plasmid. J Bacteriol 120:416423

Wong CL, Dunn NW (1974) Transmissible plasmid coding for the degradation of benzoate and $\mathrm{m}$-toluate in Pseudomonas arvilla mt-2. Genet Res (Camb) 23:227-232

Young JG, Jackman LM, Gibson F (1969) The isolation, identification and properties of 2,3-dihydro-2,3-dihydroxybenzoic acid. An intermediate in the biosynthesis of 2,3-dihydroxybenzoic acid. Biochem Biophys Acta 177:381 - 388

Young JG, Gibson F, MacDonald CG (1969) Enzymic transformation of chlorismic acid and related cyclohexadienes. Biochim Biophys Acta 192:62 - 72

Received June 11, 1987/Accepted October 30, 1987 